\title{
Safety Evaluation of Hyperbolic Arch Aqueduct Using Three- Dimensional Laser Scanning and Finite Element Analysis
}

\author{
Chengfa Deng ${ }^{1,2, *}$, Chang Xu ${ }^{3}$, Qi Xie ${ }^{4}$, and Qiang Peng ${ }^{1}$ \\ ${ }^{1}$ Zhejiang Institute of Hydraulics \& Estuary, 310020 Hangzhou, China \\ ${ }^{2}$ Zhejiang Provincial Key Laboratory of Hydraulic Disaster Prevention and Mitigation, 310020 Hangzhou, China \\ ${ }^{3}$ Zhejiang University of Water Resources and Electric Power, 310018 Hangzhou, China \\ ${ }^{4}$ Hangzhou river management terminal, 310014 Hangzhou, China
}

\begin{abstract}
The safety evaluation of the aqueduct in many years of operation is often performed to determine the structural operational behaviour so as to provide a scientific basis for further reinforcement or reconstruction. The missing of the original design data due to the long construction period provides great challenging in the structural safety evaluation of the aqueduct. Taking a hyperbolic arch aqueduct in China as an example, we first rebuilt the aqueduct model using the three-dimensional (3D) point cloud from the three-dimensional laser scanning technology. Coupled with the on-site safety inspection, the 3D finite element analysis was then performed to learn the stress performance of the aqueduct body and its supporting structures, so as to achieve the purpose of safety evaluation of aqueduct structure in a whole.
\end{abstract}

\section{Introduction}

Aqueduct is a kind of overhead water conveyance structure, which is used to convey the water flow of canal and cross over rivers, valleys, depressions, roads, etc. The first aqueduct in the world was born in the Middle East and West Asia and there is also a long history of aqueduct construction in China. For example, the famous "Feidu" canal built about 2000 years ago in the Western Han Dynasty according to the records is the aqueduct [1]. From 1950s to 1980s, a large number of aqueducts have been built in China and most of these aqueducts are still carrying out the task of water delivery to date. Due to the long time of construction and the low design standard at that time, the aqueduct operation is severely affected by various degrees of cracking, leakage and deformation $[2,3]$. As such, the need of safety evaluation for these old aqueducts is urgent. Due to the lack of relevant standards or codes for aqueduct safety evaluation, and considering the structural characteristics of the aqueduct itself, many scholars prefer to use the finite element method to analyze the aqueduct safety [4, 5]. Wang et al. [6] tested the appearance quality, concrete strength and concrete carbonation depth of the U-shaped aqueduct, which is running for 28 years. They established the ANSYS finite element model, and analyzed the internal force value of each control section of the aqueduct. Zheng [7] used three-dimensional (3D) finite element software to simulate the stress performance of rectangular aqueduct, and studied the stress and deformation distribution law of each control section of the aqueduct body.

At present, the original design data of the aqueduct is fundamental in the finite element calculation. However, the deformation may occur in the aqueduct body and its supporting structure after many years of operation, consequently the original design data based modelling cannot reflect the actual situation of the aqueduct. The worst part is the missing of the aqueduct design data. In this study, we focus on the safety evaluation of a hyperbolic arch aqueduct in China which has been running for 40 years. We first rebuild the actual scene of the aqueduct using the 3D laser scanning technology, and we then establish a point cloud data based solid structural model that included in the finite element analysis. Our results can provide a reference for similar projects.

\section{Aqueduct status testing}

The "Datangkou" aqueduct (see Figure 1) is a double curvature arch aqueduct which is built earlier in 1978 . The groove body is a rectangular groove with tie rods and ribs, with a net width of $3.82 \mathrm{~m}$, a net depth of $2.5 \mathrm{~m}$ and a tie rod spacing of $1.95 \mathrm{~m}$. The aqueduct arch frame adopts three ribs and two waves, and the main arch ring adopts constant cross-section catenary with a clear span of $22.0 \mathrm{~m}$ and a total of 3 spans. The abdominal arch adopts continuous micro bending arch with a clear span of $2.0 \mathrm{~m}$. The total length of the aqueduct is $108.9 \mathrm{~m}$, the design flow is $16.5 \mathrm{~m}^{3} / \mathrm{s}$, and the increased flow is $18.0 \mathrm{~m}^{3} / \mathrm{s}$.

Through the appearance quality inspection, we find that the aqueduct has some serious leakages at the joint of the aqueduct body, and cracks and damages on the aqueduct plate surface and at the joint of the diaphragm and the side rib as well. Following the rebound methods

* Corresponding author: 343531932@qq.com 
in [8], we tested the concrete compressive strength of the aqueduct by the method. The testing results are shown in Table 1. Considering that the aqueduct has been in operation for a long time, the age correction coefficient of the rebound value is tentatively set to be 0.9 [9]. Table 1 reveals that the estimated concrete compressive strength at the present age of each component meets the design requirements. The test of carbonation depth shows that there is a certain degree of carbonation in each component, among which the carbonation depth of the channel plate is relatively large $(36.6-46.1 \mathrm{~mm})$, which is close to the thickness of the protective layer of the reinforcement $(52-68 \mathrm{~mm})$. The carbonation depth of other components is $3.1-9.7 \mathrm{~mm}$, and this value is significantly less than the thickness of the protective layer of the reinforcement.

Table 1. Test results of concrete strength.

\begin{tabular}{|c|c|c|}
\hline Component & Detection result (Mpa) & $\begin{array}{c}\text { Design } \\
\text { standard }\end{array}$ \\
\hline $\begin{array}{c}\text { Transverse wall, } \\
\text { arch wave and } \\
\text { groove body }\end{array}$ & $18.0 \sim 34.3$ & $200^{\#}(\mathrm{C} 18)$ \\
\hline Ventral arch & 20.6 & $150^{\#}(\mathrm{C} 13)$ \\
\hline Arch rib & $29.9,39.9$ & $300^{\#}(\mathrm{C} 28)$ \\
\hline
\end{tabular}

\section{D laser scanning and data processing}

\subsection{D laser scanning}

As aforementioned, we cannot build a structural model due to the lack of complete original design data of the aqueduct. In this case, we scan the aqueduct body in the field using the German Z+F 5010C laser scanner (see Figure 1). The main characteristics of the instrument are: the maximum measuring range is $187.3 \mathrm{~m}$, the minimum measuring range is $0.3 \mathrm{~m}$, the resolution is $0.1 \mathrm{~mm}$, the vertical field of vision is $320^{\circ}$ and the horizontal field of vision is $360^{\circ}$. The overall $3 \mathrm{D}$ scanning results of the first span and the whole aqueduct are shown in Figure 2 and Figure 3 respectively.

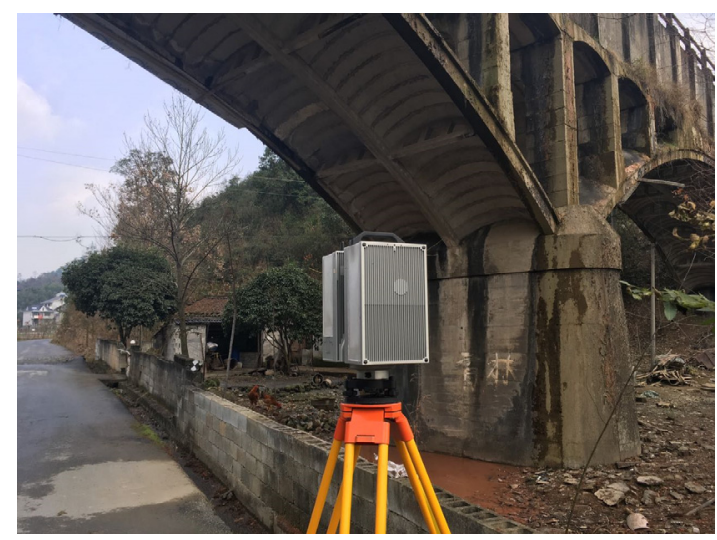

Fig. 1. 3D laser scanning for the aqueduct body

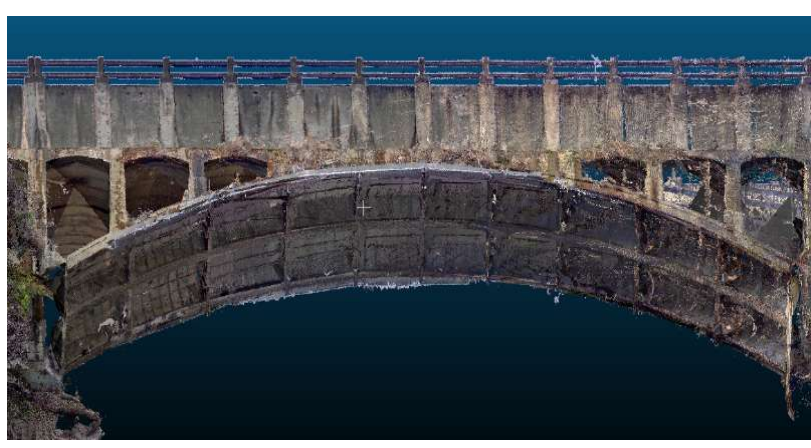

Fig. 2. 3D point cloud of first span aqueduct

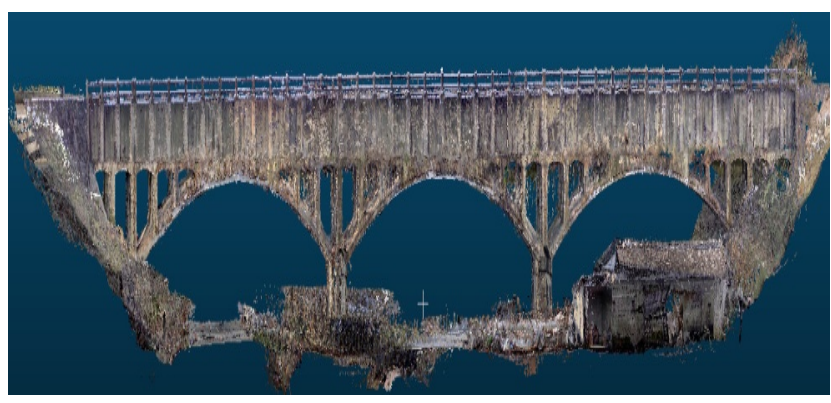

Fig. 3. Point cloud diagram of the whole aqueduct

\subsection{Data processing and accuracy analysis}

Figure 4 gives the data processing flow of the 3D laser scanning. First, the original point cloud data of different sites are registered. After some data processing (e.g., simplification, de-noising and filtering), point cloud data are then feature analyzed and processed in the reverse engineering software (e.g., Geomagic) to realize the Non-Uniform Rational B-Splines (NURBS) surface reconstruction and $3 \mathrm{D}$ reconstruction.

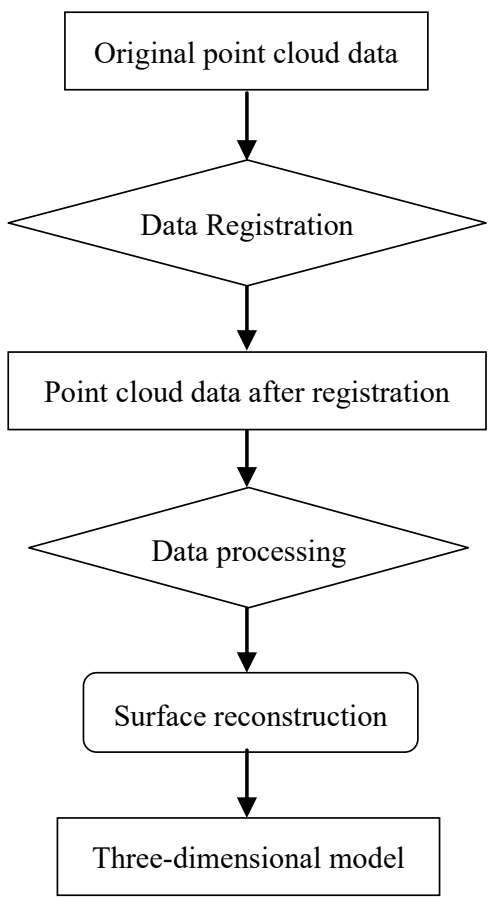

Fig. 4. Processing flow of 3D laser scanning cloud data 
Table 2 givens the model accuracy test results. According to the only available design data and field measurement results, we find that the model size of the aqueduct is basically equivalent to the design or measured value. The model accuracy is typically high, and meets the calculation requirements.

Table 2. Model accuracy.

\begin{tabular}{|c|c|c|c|c|}
\hline Component & Size & $\begin{array}{c}\text { Model } \\
\text { average } \\
\text { (m) }\end{array}$ & $\begin{array}{c}\text { Design or } \\
\text { measured } \\
\text { value } \\
\text { (m) }\end{array}$ & $\begin{array}{c}\text { Absolute } \\
\text { difference } \\
\text { (m) }\end{array}$ \\
\hline \multirow{2}{*}{ Groove body } & $\begin{array}{c}\text { Clear } \\
\text { height }\end{array}$ & 2.520 & 2.50 & 0.02 \\
\cline { 2 - 5 } & Clear width & 3.775 & 3.82 & 0.045 \\
\hline Ventral arch & Clear width & 2.035 & 2.00 & 0.035 \\
\hline \multirow{2}{*}{ Arib } & $\begin{array}{c}\text { Middle rib } \\
\text { width }\end{array}$ & 0.267 & 0.26 & 0.007 \\
\cline { 2 - 5 } & Rib width & 0.228 & 0.22 & 0.008 \\
\hline Main arch ring & Clear span & 22.01 & 22.0 & 0.01 \\
\hline
\end{tabular}

\section{3D finite element analysis}

\subsection{Finite element model}

The 3D reconstruction model is imported into the finite element software for mesh generation. Considering the structural symmetry characteristic of the aqueduct and for the sake of reducing the calculation time, we only modelled and analyzed the first span here. The 3D finite element model is subdivided into 143582 tetrahedral elements with 4 nodes in total (see Figure 5). The estimated compressive strength of each member at the present age meets the design requirements, and the design elastic modulus is adopted in the calculation model.

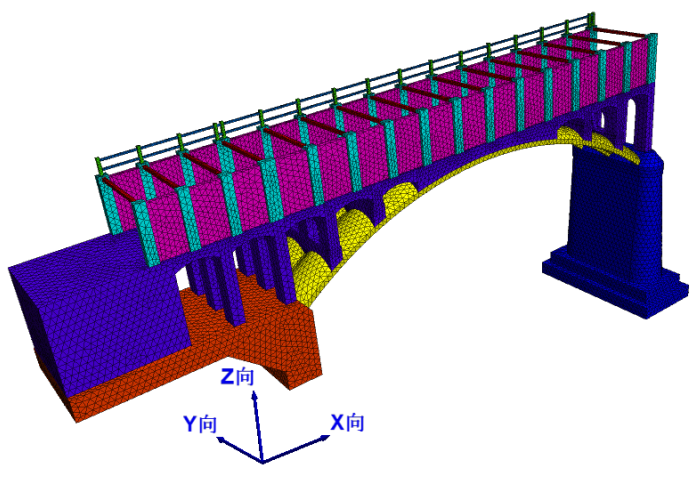

Fig. 5. Finite element analysis model of aqueduct

\subsection{Finite element Analysis}

In order to estimate the maximum stress performance of the aqueduct, full tank condition is selected for calculation and analysis. Table 3 gives the stress calculation results of each control section. Figure 6 and Figure 7 shows the maximum principal stress and the minimum principal stress nephogram. We find that the maximum main compressive stress of the main arch ring is $5.185 \mathrm{MPa}$ under the full groove condition, which appears at the arch foot upstream of the middle rib and less than the standard value of the concrete axial compressive strength $(18.7 \mathrm{MPa})$. The minimum main tensile stress of the main arch ring is $0.895 \mathrm{MPa}$, which appears at the top of the middle rib arch and less than the standard value of the concrete axial tensile strength (1.9MPa).

Table 3. Stress calculated values of control sections

\begin{tabular}{|c|c|c|c|}
\hline Section & Position & \begin{tabular}{|c|} 
Maximum \\
principal stress \\
value (Mpa)
\end{tabular} & $\begin{array}{c}\text { Minimum } \\
\text { principal stress } \\
\text { value (Mpa) }\end{array}$ \\
\hline \multirow{3}{*}{$\begin{array}{l}\text { Upstream } \\
\text { arch foot }\end{array}$} & Left arch & -5.067 & -0.187 \\
\hline & Middle arch & -5.185 & -0.313 \\
\hline & Right arch & -5.105 & -0.147 \\
\hline \multirow{3}{*}{$\begin{array}{l}\text { Upstream } \\
1 / 4 \text { span }\end{array}$} & Left arch & -1.261 & 0.030 \\
\hline & Middle arch & -1.442 & 0.028 \\
\hline & Right arch & -1.240 & 0.019 \\
\hline \multirow{3}{*}{ Vault } & Left arch & 0.050 & 0.547 \\
\hline & Middle arch & 0.006 & 0.895 \\
\hline & Right arch & 0.010 & 0.730 \\
\hline \multirow{3}{*}{$\begin{array}{c}\text { Downstream } \\
1 / 4 \text { span }\end{array}$} & Left arch & -0.955 & 0.321 \\
\hline & Middle arch & -0.770 & 0.179 \\
\hline & Right arch & -1.132 & 0.066 \\
\hline \multirow{3}{*}{$\begin{array}{c}\text { Downstream } \\
\text { arch foot }\end{array}$} & Left arch & -3.822 & -0.102 \\
\hline & Middle arch & -3.669 & -0.042 \\
\hline & Right arch & -4.091 & -0.291 \\
\hline
\end{tabular}

Figure 8 shows the deflection nephogram of the aqueduct under full condition. We find that the deflection of the main arch ring increases gradually from the arch foot to the middle of the span under the full groove condition, and the maximum deflection appears in the middle rib of the arch crown $(5.71 \mathrm{~mm})$. The result is far less than that of the maximum deflection allowed by the code (i.e. $\mathrm{L} / 800=27.5 \mathrm{~mm}$ ).

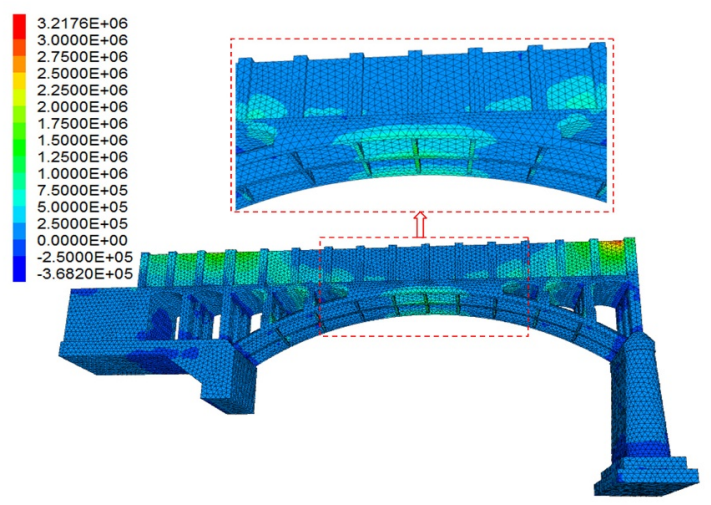

Fig. 6. Maximum principal stress nephogram 


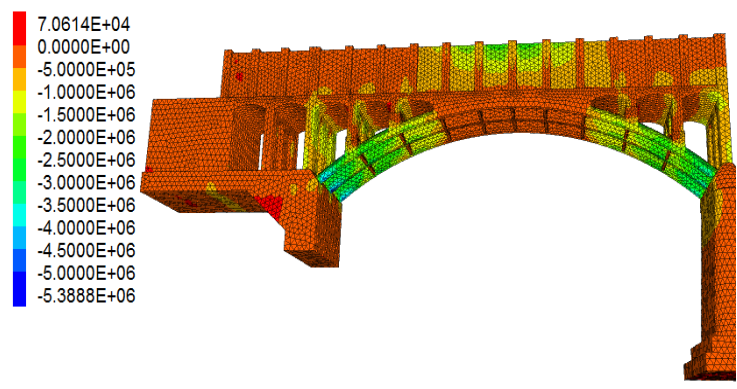

Fig. 7. Minimum principal stress nephogram

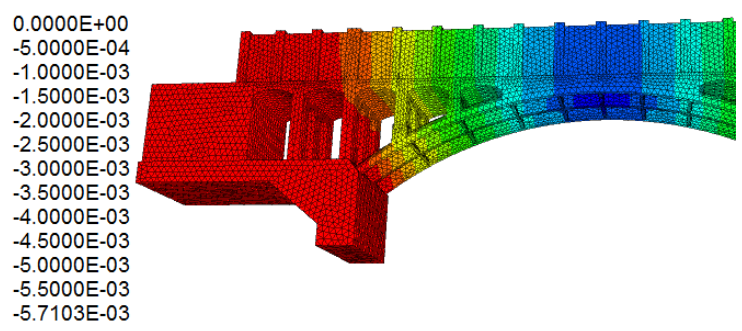

Fig. 8. Deflection nephogram of aqueduct

\section{Conclusions}

This paper discusses the application of the 3D laser scanning combined with the finite element analysis to evaluate the safety of the hyperbolic arch aqueduct. A case study of a hyperbolic arch aqueduct in China which has been running for 40 years is provided. The results show that the solid structure model in the finite element analysis can be precisely built by the $3 \mathrm{D}$ point cloud model using the 3D laser scanning technology. The results of the finite element numerical calculation show that the maximum principal stress, the minimum principal stress and the maximum deflection of the main arch ring of the aqueduct are less than the design standard, indicating that the whole aqueduct supporting structure (arch rib) is still in a safe state. Our results can provide a reference for other similar engineering projects.

\section{Acknowledgments}

This study was in part supported by the National Natural Science Foundation of China (Grant No. 51479178 and 41804007).

\section{References}

1. Zhu Huizhu, Chen Deliang, Guan Fengnian. Aqueduct. Beijing: China Water Conservancy and Hydropower Press (2004)

2. Gu P, Wang L, Deng C, et al. Review of typical failure characteristics of aqueduct structures in China. Advances in Science \& Technology of Water Resources, 37(5): 1-8 (2017)
3. Feng Z . Study on the Appraisal and Evaluation of Aqueduct Security in the Irrigation Area of Ningxia. Yellow River, 38 (7): 134-137 (2016)

4. Wang Yahong, Wang Zhengzhong, Li Xiaohui, et al. Checking of Lishui ditch aqueduct body bearing structure [J]. Journal of Northwest Agriculture \& Forestry University (Natural Science Edition), 37 (12): 22-28 (2009)

5. Han Jianping, Dong Xiaojun, Luo Weigang, et al. Durability Evaluation on An Existing RC Arched Vierendal Truss Aqueduct[J]. Earthquake Resistant Engineering and Retrofitting, 31 (2): 71-75(2009)

6. Wang Xingmeng, Lu Yiyan, Jin $\mathrm{Lu}$, et al. Evaluation of Structural Performance of Wangchuan River Diversion Aqueduct. Journal of Yangtze River Scientific Research Institute, 34 (11): 116-119 (2017)

7. Zheng Chongyang, Peng Hui, Ren Deji. ThreeDimensional FEM Analysis on Jihe River Aqueduct in the Middle Route of South-to-North Water Diversion Project. Journal of Yangtze River Scientific Research Institute, 30 (5): 86-91(2013)

8. JGJ/T23-2011, Technical specification for inspecting of concrete compressive strength by rebound method. Beijing: China Architecture\& Building Press ( 2011)

9. GB50292-2015, Standard for appraisal of reliability of civil buildings. Beijing: China Architecture\& Building Press ( 2015) 